\title{
Knowledge, attitudes and practices of hospital cleaning services staff towards Coronavirus Disease-2019 (COVID-19) in a Middle Eastern country: A web-based cross-sectional study
}

Dalal Youssef ( $\square$ dalalyoussef.esu@gmail.com )

Ministry of Public Health

Linda Abou Abass

Ministry of Public Health

Hamad Hassan

Ministry of Public Health

\section{Research Article}

Keywords: knowledge, attitudes, practices, environmental cleaning staff, Lebanon, COVID-19

Posted Date: June 21st, 2021

DOl: https://doi.org/10.21203/rs.3.rs-576799/v1

License: (c) (1) This work is licensed under a Creative Commons Attribution 4.0 International License.

Read Full License 


\section{Abstract}

Background Hospital cleaners are the unsung heroes in the fight against the COVID-19 pandemic. This study aims to assess the knowledge, attitudes, and practices (KAP) of hospital cleaners towards COVID19 and to determine factors associated with good practices.

Methods A cross-sectional study was conducted in Lebanon between 1st and 14th November 2020. Data was collected through an online survey that was sent to governmental-run and private hospitals. The questionnaire consisted of socio-demographic characteristics, clinical information, and KAP of hospital cleaners towards Covid-19. The collected data was exported to SPSS for analysis. The relation between nominal variables was tested using the chi-squared test. The variables in bivariate analysis with $\mathrm{p}$ value $<0.2$ were entered into multivariable logistic regression. Adjusted odds ratio and their $95 \%$ confidence intervals were reported. The level of statistical significance was set at a $p$-value $<0.05$.

Results A total of 453 cleaners completed the survey of which $54.3 \%$ were females. Most of the participants had a good level of COVID-19 knowledge (98\%) and good preventive practices (89.7\%). Regarding attitude, $90.7 \%$ had a positive attitude toward health facilities, $78.8 \%$ towards cleaning and disinfection, and $73.5 \%$ towards health authorities. Sociodemographic characteristics including younger age, higher levels of education, working in private hospitals, and having more than 3 years of experience were positively associated with good preventive practices. Our results also showed that participants with good knowledge about COVID-19, COVID-19 prevention and treatment, cleaning and disinfection process, and COVID-19 risk factors had a higher likelihood of positive preventive practices. Finally, a positive attitude towards health facilities, health authorities, and cleaning and disinfection were positively associated with good practices.

Conclusion Our results indicate that cleaners have a high level of knowledge, expressed positive attitudes towards health facilities and health authorities, and good preventive practices. Understanding the determinants of cleaning performance is critical in tailoring interventions to improve hospital cleaning.

\section{Introduction}

The swift worldwide spread of the Coronavirus disease 2019 (COVID-19) with associated mortality and morbidity is worrisome (1). Although person-to-person transmission through close contact with an infected person is the most important driver of COVID-19 widespread, transmission from contaminated surfaces could be also a potential source of infection $(2,3)$. In general, surfaces become contaminated when virus-containing droplets land on them or when someone with contaminated hands touches these surfaces. Recent studies indicate that COVID-19 can remain viable for between eight hours and several days depending on the type of surface. It can remain on plastic for up to 3 days, stainless steel 2-3 days, and cardboard 24 hours (4). Hence, the vital role of decontamination of the health care environment to reduce indirect transmission of COVID-19 as well as to provide health care workers (HCWs) and patients with decent and clean places to work and get medical care (5). 
Decontamination includes cleaning, disinfection, and the safe disposal of waste. However, cleaning is the procedure of eliminating contaminants and disinfection is the process by which any microorganisms that persist after cleaning are reduced to a level at which they are not detrimental (6). Behind this enhanced hygiene are the hospital environmental service workers (ESWs) who play an important role in interrupting the chain of infection (7). Particularly, the cleaners are the unsung heroes in the fight against the COVID19 pandemic.

Given that the pandemic has had devastating consequences for a wide variety of occupations, housekeepers and cleaning staff have been among the hardest hit. They are responsible for deep cleaning and disinfecting the surfaces that host potentially dangerous germs and viruses. However, cleaning hospitals is replete with challenges. The cleaners of coronavirus isolation rooms and intensive care units run a daily gauntlet of infection risks to ensure that hospital spaces run smoothly, and they are responsible to prevent the spread of the disease in hospitals. However, their status as unskilled laborers in a behind-the-scenes role has left them out of the public eye. Medical staffers are lauded worldwide for their lifesaving work during the pandemic, cleaners are rarely mentioned.

Since cleaning staff are usually exposed to occupational hazards including COVID-19, there is a crucial need to improve their knowledge and to monitor closely their practices which minimize the risk of infection. Understanding and targeting their practices may inform strategies to improve environmental cleaning (8).

In Lebanon, there is a lack of data concerning the number of cleaning staff infected by COVID-19 among hospitals but according to the epidemiological surveillance unit data, no deaths were reported among this category. Although those previous studies have evaluated the knowledge and practices of different health care workers toward COVID-19 including physicians (9), dentists (10), pharmacists (11) and nurses (12) no studies have focused on the practices of hospital services staff members, particularly housekeepers.

In the context of the COVID-19 pandemic, it is of great interest to conduct this study to shed light on the level of knowledge, attitudes, and practices of cleaning services staff working in the Lebanese hospitals and to determine factors associated with good practices.

\section{Methodology}

\section{Study tool and design}

Following the recommendation of the Lebanese government to the public to minimize face-to-face interaction during the pandemic period which hinders the feasibility of performing a field hospital-based survey, potential respondents were electronically invited to participate. A cross-sectional study, using an online survey, was conducted during the rise of COVID-19 cases in Lebanon between 1st and 14th November 2020.

\section{Questionnaire development}


For the first stage, a meticulous study of the literature was conducted to discover available resources on $\mathrm{KAP}$, as well as to identify relevant items and scales in existing questionnaires on the prevention of COVID-19. The knowledge section was developed based on the etiology, transmission, risk, prevention of COVID-19 in addition to cleaning and disinfection procedures $(13,14)$. However, the attitude section of the questionnaire was developed based on the theory of Health Belief Model (HBM) (15), while the practice was based on the cleaning and disinfection at health facility recommended by the World Health Organization (WHO) and the Centre for Disease Control and Prevention (CDC) $(14,16)$. A panel of experts which consisted of an epidemiologist, a microbiologist, a hygienist, and a medical statistician select the best items for clarity of the questions and accuracy of the knowledge, attitude, and practice domains and its interpretability. This panel also helped in identifying and judging the content validity (relevance, coverage, and representativeness) of the items initially selected for inclusion in the questionnaire. The original draft of the questionnaire was developed in English and then translated to the slang Arabic language which is the official national language in Lebanon based on the standard translation guidelines. It underwent two forward translations by a sworn translator and an epidemiologist. Subsequently, the two sets of translated Arabic questionnaires were subjected to a backward translation into English by another language communication expert as well as an epidemiologist. This process aimed to recognize and harmonize the translated items from the original English version and to produce an accurate Arabic version of the questionnaire (17). Face validity was conducted on 10 cleaners and housekeepers to evaluate the understanding and clarity of the questionnaire. Their various responses and understanding regarding the questions, how it was presented (layout and setting) and lack of vagueness were assessed. A revised and finalized version of the questionnaire was produced from the findings of the face validation for use throughout the rest of the research. The questionnaire is self-administered and consisted of questions that overviewed (1) socio-demographic characteristics; (2) Clinical information; (3) knowledge of Cleaning and disinfecting; (4) attitude towards Covid-19; and (5) prevention practices towards Covid- 19 of the hospital cleaning services staff.

1-Socio-demographic characteristics including age, gender, nationality, marital status, level of education, year of experience in cleaning, and the type of hospital where the participant works

\section{2-Clinical information including health status and presence of comorbidities}

3- Knowledge section: Five dimensions with a total of 26 items were designed to measure cleaner's knowledge about nature and symptoms COVID-19, the transmission of COVID-19, prevention and treatment, factors amplifying the risk of infection, cleaning, and disinfection. All the items were answered on a true/false basis and an additional "do not know" option. A correct response had a value of ' 1 ' and a "wrong" or don't know response had a value of ' 0 '. Each correctly chosen choice had a value of 1 , and each wrongly chosen and 'don't know response' had a value of 0 . Hence, the aggregate score for all 26 knowledge questions would range from 0 to 26 points. Participants 'overall knowledge was categorized using modified Bloom's cut-off point, as good if the score was between 60 and 100\% (16-26 points) and poor if the score was less than $60 \%$ ( $<16$ points) 
4- Attitude section: Three dimensions were used to assess cleaners' attitudes: the first focusing on their attitudes toward health facilities, the second concentrating on health authorities, and the last one on cleaning and disinfection. Responses to questions related to attitude were graded on a 3-point Likert scale, an agreement scale ranging from ' 1 ' for disagree to ' 3 ' for agree. A point of 1 was given to the options "agree" answer while disagree or neutral responses were given a 0 point. The level of attitude in each domain was categorized using the original Bloom's cut-off point, as positive if the score was 60$100 \%$ and negative if the score was less than $60 \%$.

5- Practice section: A total of 21 items constitute this section. Each item was answered on 3 points Likert scale: "never", "occasionally", and "all the time". This scale was used to get precise responses about the IPC measures adopted by the cleaners as follows: never if not at all, occasionally if once or more in a while and all the time. The answer "all the time" was assigned 1 point whereas "never" and "occasionally" answers were assigned 0 points. The questionnaire was validated by doing a pre-test on $5 \%$ of the sample before the actual data collection period. Survey flow, functionality, and language were based on pre-test feedback. The average time for filling the survey was 8 minutes.

\section{Sample size calculation}

The sample size was calculated using the online RAOSOFT sample size calculator web survey software (http://www.raosoft.com/samplesize.html). Based on an estimated population of 4000 housekeepers actively practicing at the health facilities level, a $95 \%$ confidence level and an absolute error of $5 \%$, the minimum required sample size would be 351 participants.

Data collection: An online questionnaire using a Google doc was emailed to governmental-run and private hospital directors in different parts of the country. Then, designated focal persons working in Lebanese hospitals were contacted via phone call and notified about the survey and its purpose. Upon their agreement to participate, the link of the study was sent through "WhatsApp" to the designated focal person. The survey link was then disseminated by the respective hospitals to the cleaners and housekeepers working in their health facility through social media (mainly WhatsApp). The survey link stated that all cleaners who were working in Lebanese hospitals, able to read and write in Arabic were eligible to take part in the survey. In addition, the link includes also a brief introduction to the background, the objective of the survey, and instructions for filling out the questionnaire. Cleaners who were seriously ill and on annual leave during data collection were excluded.

\section{Ethical approval:}

Written informed consent was obtained from each participant. Participation in the survey was entirely voluntary and all information was gathered anonymously and was kept strictly confidential. As individual participants cannot be identified based on the presented material, this study caused no plausible harm or stigma to participants. The study design assured adequate protection of study participants, and neither includes clinical data about patients nor configures itself as a clinical trial. Hence, this study was exempted from ethical approval in the Lebanese Ministry of Public Health. 


\section{Data analysis:}

The collected data were exported to a Microsoft Excel 2016 for cleaning and coding. The cleaned data were exported and analyzed using the statistical software SPSS (Statistical Package for Social Sciences), version 22.0. Descriptive statistics were reported using frequency with percentages for categorical variables. Single-item knowledge questions were summarized by the percentages of correct responses. To check scale reliability, Cronbach's alpha was conducted on all knowledge, attitudes, and practices scores. Responses to questions relating to the attitudes and role of cleaning were tabulated in terms of the percentages of disagree, agree, and neutral answers. Bivariate analysis was performed to examine factors associated with the dependent variable (good practice) and the independent variables. The relation between nominal variables was tested using the chi-squared test. The variables in bivariate analysis with $\mathrm{p}$-value $<0.2$ were entered into multivariable logistic regression. Adjusted odds ratio and their $95 \%$ confidence intervals were reported. The final logistic regression model to determine the predictors for vaccination uptake was reached after confirming the adequacy of the data using the Hosmer and Lemeshow test. The level of statistical significance was set at a p-value $<0.05$.

\section{Results}

\section{1-Baseline characteristics of the study participants}

Table 1 shows the baseline characteristics of the participants. A total of 453 cleaners have completed the survey of which $54.3 \%$ were females. Around third of them were aged between (21-30) years old and the majority of them were Lebanese (82.34\%), married (65.56\%), with an educational level of school degree or less (68.65\%). They mostly had a good health status (89.95\%) and only $27.59 \%$ of them suffered from comorbidities. About two-thirds of the participants worked in private hospitals and nearly half of them have experience of 3 years or more in cleaning in health facilities. Almost $80.79 \%$ of them have an income of less than 1 Million Lebanese pounds.

\section{2- Cleaners self-reported knowledge}

Almost $98 \%$ of surveyed cleaners had a good overall knowledge score ( $\geq 60 \%)$. Figure 1 illustrates cleaners' knowledge score by knowledge domains. The majority of respondents were aware and wellinformed with more than $90 \%$ of them having good knowledge scores in all targeted knowledge domains that comprise nature and symptoms COVID-19, its mode of transmission, its prevention and treatment, factors amplifying the risk of infection, and decontamination procedures. Table 2 describes the cleaner's answers towards COVID-19 and cleaning knowledge items. Despite that most of cleaners (90\%) have answered correctly to the big majority of knowledge items, some questions remained less recognized and recorded the lowest rate of correctness such as those related to the transmission of COVID-19 by urine and feces of an infected person where only $46.4 \%$ have answered correctly, the availability of specific treatment for COVID-19 (66.9\%) and the need to reduce the frequency of cleaning of the room of COVID19 patient $(67.1 \%)$. Similarly, items that focused on the requisite to rinse the surface after the application of disinfectant (51.7\%) and those related to the amplification of COVID-19 risk of infection such as the 
concentration of virus (69.3\%) and the time since the infected person left the place $(72.8 \%)$ were not well known compared to other knowledge items.

\section{3- Cleaners' attitudes:}

\subsection{Assessment of Cleaners attitudes towards health facility}

Table 3 describes cleaners' attitudes towards health facilities and health authorities. The majority of cleaners $(87.7 \%)$ agreed that patient safety is a priority in the hospital where they work and that hospital cares about their safety $(90.7 \%)$. In addition, the hospital provided them with the equipment and supplies needed for cleaning and disinfection (90.7\%). Similarly, they also considered that IPC measures were well implemented at the hospital level (87.2\%) and that the health facility has well played its role in raising awareness about the risk of catching COVID-19 and how to prevent it (90.4\%). Around half of cleaners $(47 \%)$ stated that the hospital where they work is continuously looking to finding new ways to improve hygiene. However, $33.8 \%$ of them considered that the hospital does not appreciate any further effort exert on their part, and $29.8 \%$ of them declared that even if they do their best, the hospital will not appreciate it. Similarly, around $28 \%$ of cleaners pondered that hospital does not take much interest in them and ignores their complaints and requests.

\subsection{Cleaners' attitudes towards health authorities}

Out of $453,321(76.9 \%)$ cleaners deliberated that Lebanese health authorities have played their role in fighting COVID-19, particularly in a health care setting by providing PPEs and performing training. Besides, the majority of them (66.2\%) declared that they have confidence that the government can win the battle against the COVID-19 (Table 3).

\subsection{Cleaners' attitudes towards cleaning and disinfection}

More than $85 \%$ of cleaners considered that regular hand washing, wearing PPEs, cleaning and disinfecting surfaces are effective measures for eliminating COVID-19 and could prevent the infection. Figure 2 displays the cleaner's attitudes scores. The majority of cleaners had a good attitude towards health facilities, health authorities, and IPC precautions.

\section{Cleaners' practices:}

Table 4 shows cleaners' practices items. The majority of cleaners stated that they always followed the IPC standard precautions such as hand hygiene practices (90.7\%), social distancing (75.7\%), avoiding the presence in crowded places (85.7\%), wearing a face mask at the hospital (91.4\%), avoiding touching surfaces then touching eyes or faces (92.5\%) and respecting cough and sneeze etiquette $(94 \%)$ as well. Moreover, $92.4 \%$ of them reported compliance with the MOPH recommended prevention measures.

In respect to cleaning and disinfection, $87.6 \%$ of surveyed cleaners reported that they always checked the availability of the needed cleaning supplies with their supervisor before starting work. More than $80 \%$ of them kept the room aerated and followed permanently the manufacturer's instructions to ensure that 
disinfectants are prepared and handled safely. Besides, around $90 \%$ of cleaning staff stated that they cleaned and disinfected common areas at hospitals in addition to the frequently touched objects (handles, elevator buttons, handrails, doorknobs ...) all the time. In addition, the majority of surveyed cleaners $(94.3 \%)$ reported careful and appropriate handling of laundry to mitigate the risk of potential transmission where $89.2 \%$ of them put textiles, linens, and clothes in special, marked laundry bags and $83.7 \%$ washed laundry in warm cycles $\left(60-90^{\circ} \mathrm{C}\right)$ with the usual detergents.

Concerning the use of PPE, $94.7 \%$ of cleaners stated that they always wear appropriate PPE when visiting the COVID-19 patient room for cleaning and $91.6 \%$ of them reported proper donning and doffing of PPE. Also, more than $90 \%$ of cleaners always follow recommended hand hygiene practices before and after putting PPEs or cleaning. The majority of them (87.9\%) attended all the times regular training sessions about IPC during COVID-19 as well. Regarding waste management, $93.4 \%$ of cleaners reported that they always managed efficiently waste by placing disposable items (hand towels, gloves, medical masks, and tissues) in a container with a lid and followed the hospital action plan and the national regulations related to waste management. However, only $63.6 \%$ of them constantly followed COVID-19 news.

\section{Sources of information}

The most used sources of information cited by cleaners were health care professionals (66.8\%), health authorities (66.2\%), and social media (61.6\%) (figure3). Whereas, the most reliable sources of information as ranked by the cleaners were the MOPH (67.5\%) followed by printing materials (55.6\%) and trainings (54.7\%) (Figure 4).

\section{Factors associated with cleaners' good practices}

Table 5 represents the multivariable logistic regression of the factors associated with cleaners' good practices. Our results showed that the odds of good practices were not associated with gender, marital status, or suffering from any comorbidity. Age was found to be associated with good practices. Older participants aged more than 40 years were less were less likely to adopt good practices ( $\mathrm{aOR}=0.051$ with $95 \% \mathrm{Cl}(0.005$ to 0.576$)$ comparing to their counterparts. However, cleaners having an educational level of a secondary degree or more were 2.869 times more likely to take good practices comparing to respondents having the lowest educational level (aOR=2.869 with $95 \% \mathrm{Cl}(0.871$ to 9.441$)$ ). Besides, cleaners working in private hospitals ( $\mathrm{aOR}=10.083$ with $95 \% \mathrm{Cl}(3.340$ to 30.436$)$ ) and having more than 3 years of experience in hospital cleaning ( $\mathrm{aOR}=12.942$ with $95 \% \mathrm{Cl}(4.214$ to 39.747$)$ ) were positively associated with the adoption of good practices. In respects of knowledge, cleaners showing a good knowledge level about COVID-19 domain (aOR=9.076 with $95 \% \mathrm{Cl}$ (1.895 to 43.463)), prevention and treatment of COVID-19 (aOR=10.717 with $95 \% \mathrm{Cl}$ (1.594 to 22.051)), cleaning and disinfection (aOR=3.934 with $95 \% \mathrm{Cl}(1.099$ to 14.126$)$ ), and factors affecting the risk of COVID-19 (aOR=7.397 with $95 \% \mathrm{Cl}$ (1.569 to 29.463$)$ ) were positively associated to good practices. Moreover, cleaners having a positive attitude towards health facilities ( $\mathrm{aOR}=3.939$ with $95 \% \mathrm{Cl}(1.099$ to 14.126$)$ ), were 3.939 more likely to have good practices. Similarly, respondents with a positive attitude towards health authorities and government (aOR=3.309 with $95 \% \mathrm{Cl}(1.106$ to 9.863)) were 3.309 times more likely to have good 
practices. Finally, participants with a positive attitude towards cleaning and disinfection were 14.481 more likely to implement good practices during their work.

\section{Discussion}

COVID-19 pandemic stressed the utmost importance of hygiene and infection prevention in the fight against emergent disease, particularly at the hospital level. Hence, it shined a rare spotlight on the critical tasks performed by, the often-invisible workforce, represented by the hospital cleaners. To the best of our knowledge, this is the first national Lebanese study aiming to explore environmental cleaning staff knowledge, attitudes, and practices toward cleaning and disinfection during the COVID-19 pandemic. It also reveals cleaners' insights, henceforth allowing us to better understand the gaps and weak aspects in practices to be targeted in future interventions.

The main findings of our study were that the bulk of surveyed cleaners (98\%) had a good overall knowledge score and could be qualified as 'aware and abreast' in different knowledge areas related to the nature and symptoms of COVID-19, its mode of transmission, its prevention and treatment in addition to the factors amplifying the risk of infection and decontamination procedures. Our results were consistent with the findings of a study conducted among healthcare workers (HCWs) in Ethiopia where almost $84.7 \%$ of them were knowledgeable (18). Similar results were found in a study done in Addis Abeba (19). However, our findings were higher than the knowledge score reported in studies conducted in Palestine (53.9\%) and Iran hospital, $(57 \%)(20,21)$. This can be due to sampling size, sociodemographic difference, and different indexes used to assess their knowledge. While a lot of studies have focused on various aspects of this topic among other HCWs none of them deal with the cleaner's knowledge and application of infection control principles and cleaning practices of environmental services staff members. They are largely absent in the literature which make comparisons not possible.

However, some information remained not well-recognized by the cleaners such as the transmission of COVID-19 via urine or feces and the availability of specific treatment for COVID-19. However, based on the available evidence, the exposure to feces or wastewater has not been implicated as a transmission vector of COVID-19 despite the presence of the virus in stool and rarely in urines (22). Besides, the availability of specific treatment is time-bounded and under continuous trial. Similarly, not all cleaners were conscious that there is a need to reduce the frequency of the COVID-19 patient room cleaning. Despite that hygiene during the COVID-19 pandemic should be enhanced, yet there is also a need to establish a sense of balance between performing cleaning and reducing the risk of exposure to COVID-19. Comparing to other knowledge items, cleaners were not all aware of the factors related to the amplification of COVID-19 risk of infection. Hence, raising awareness about the factors affecting the risk of COVID-19 infection would help cleaners to better prevent the infection.

Similarly, the vast majority of respondents indicated a high level of agreement to questions concerning the importance of cleaning in mitigating infections for patients and their families. Besides, cleaners were 
aware of what is expected from them, and they allocated a high priority for patient safety in their organization.

In respect to attitude, the bulk of cleaners have a positive attitude towards health facilities where the majority of them considered that hospital prioritized patient safety and personal safety. Hospitals provided them with the gear and supplies needed for cleaning and disinfecting, applied the IPC measures, and raised awareness about the risk of catching COVID-19. This positive attitude could be associated with the good knowledge score owned by cleaners which are supported by the study in Iran (23). However, attitudes and beliefs about cleaners' jobs may impact their intent to clean and in turn the effectiveness of their efforts. Hence, the importance of understanding and addressing these attitudes and beliefs used to inform approaches for continuous upgrading of environmental cleaning (7). Similarly, cleaners indicated a high level of agreement to questions about the importance of cleaning in preventing infection, knowing what is expected of them, and indicating a high priority for patient safety in their organization. Our results were in line with the results of studies conducted in Canada and the United States that also acknowledged that environmental services workers (ESW) believed their work was important to keep patients safe and that cleaners take pride in their work and are committed to patients and families (24). Interestingly, in our study, most respondents highlighted the importance of receiving feedback on their performance, despite that most of them stated that regular feedback is absent.

However, our findings reveal that many cleaners do not feel appreciated by the hospital and other HCWs for any further effort exert on their part. More than a fourth of them considered that the hospital does not take much interest in them and ignores their complaints and requests. This perceived lack of appreciation and this absence of recognition of the value of their work may hamper some cleaners from carrying out their responsibilities and impact negatively their performance. Similar results were reported in a study conducted in New York among ESW (24). Thus, there is a perceived lack of organizational support, feedback, and investment in cleaning resources. The attitudes of environmental services staff members should not be ignored, and understanding the determinants of cleaning performance is critical in tailoring interventions to improve hospital cleaning and reduce the risk of infection transmission.

Notably, most of the cleaners had positive attitudes towards Lebanese health authorities and considered that the government has fulfilled their roles in fighting COVID-19, particularly in health care settings. Positive attitudes and high confidence in the control of COVID-19 can be understood by the Lebanese government's response in taking stringent control and precautionary steps including the lockdown, and suspension of all domestic and international flights, and prayer at mosques. Similarly, the vast majority of cleaners have a positive attitude towards IPC including hand washing, wearing PPEs, cleaning and disinfecting surfaces, and considered it as effective measures for preventing the COVID-19 infection.

Based on cleaners' responses, the majority of cleaners always followed the IPC standards such as hand hygiene practices, social distancing, avoiding their presence in crowded places, wearing a face mask at the hospital, avoiding touching surfaces then touching eyes or faces, and respecting cough and sneeze etiquette as well. Moreover, $92.4 \%$ of them reported compliance with the MOPH recommended prevention measures. The high score of self-reported compliance is comparable to a previous self-report study 
targeting other HCWs (25). However, studies that used observation methods for data collection reported lower compliance rates (26) .

In respect to cleaning and disinfection, the majority of surveyed cleaners followed recommended good practices starting by checking the availability of the needed cleaning supplies and gear before starting work, keeping the room ventilated, and following the manufacturer's instructions to ensure that disinfectants are handled safely. They also cleaned and disinfected common areas at hospitals,the frequently touched objects and carefully handled laundry. Concerning the use of PPE, more than $90 \%$ of cleaners declared that they always wear appropriate PPE when visiting the COVID-19 patient room or COVID-19 unit for cleaning accompanied by proper donning and doffing of PPEs combined to hand hygiene practices. Moreover, a large proportion of cleaners implemented efficient waste management and followed the hospital action plan and the national regulations related to waste management. However, such statements could be embellished and influenced by social desirability. Hence the importance of conducting a field study to closely observing adopted practices.

Our findings showed also that the majority of cleaners always attended regular training sessions about IPC during the COVID-19 pandemic. This finding could explain the good knowledge and practice score owned by surveyed cleaners given the fact that training on current guidelines could upgrade the knowledge and skills of cleaners in that they would easily understand basic standards of practice and implement them consistently. Besides this, up-to-date knowledge and skills regarding cleaning and disinfection could also increase the confidence of cleaners in complying with recommended guidelines.

More than half of cleaners stated that they constantly followed COVID-19 news. One peculiar finding that social media was cited as the most used source of information. Although these platforms provide an easy way to get the information, they can also be a source of fake news and panic (27). Thus, it is highly recommended for cleaners to seek information from scientific and authentic platforms On the other hand, the most reliable sources of information as ranked by the cleaners were the MOPH followed by the printing materials. Hence, government involvement in providing real-time emergency information during an infectious disease outbreak contributes to protective behavior engagement(28).

Gender, marital status, and suffering from any comorbidity were not associated with the adoption of good practices. However, good practices were negatively associated with increasing age practice, cleaners whose age 31 years and above were less likely to adopt good practices infection prevention than their counterparts aged 21-30 years. Inconsistent results were reported in other studies (29-31).

Our results also revealed that the working experience was another strong predictor of good practices. On other words,cleaners who had work experience of more than 3 years were four times more likely to have good practices in cleaning and disinfection compared to their counterparts with less than three years of experience. Thus, as the number of years of practice increases; cleaners are exposed to repeatedly hazards and became more experienced through working with senior staffs. 
Regarding educational level, cleaners with increased educational level adopted good practice compared to those with lower educational level. This result is in line with a study conducted in Ethiopia where a higher educational level was associated with IPC activities (32). The possible reason might be due cleaners having higher educational levels could have better opportunities to access local and international information, and training platforms than their counterparts, hence they may adopt good practices.

Besides, this study revealed that cleaners working in private hospitals were 10 times more likely to adopt good practices. This comes in line with a study conducted in Bangladesh where HCWs working in private hospitals (33). Private hospitals might have ensured regular administrative supervision and monitoring of cleaners in addition to intensive training about cleaning and disinfection, PPEs proper use, and waste management. However, private hospitals can ensure better quality service than government hospitals because they generate their financial resources from patients.

Knowledge is the foundation of everything, and in this study, cleaners who have good COVID-19 knowledge adopted good practices towards COVID-19 infection and prevention. Hence, Knowledge is a prerequisite for promoting preventive measures and enhancing good practices towards the fight against the disease.

Given that attitude has long been recognized as a factor leading people to perform a particular behavior, cleaners having a positive attitude towards health facilities or health authorities were more likely to have good practices. Having a positive attitude towards cleaning and disinfection was the main predictor factor for good practices at work.

Cleaners' attitudes and beliefs about the importance of cleaning and disinfecting may impact their intent to clean and in turn the effectiveness of their efforts. Several studies demonstrated the control of infection following the adoption of enhanced cleaning and disinfection approaches (34).

\section{Limitations of study}

Several limitations should be acknowledged in our study. Firstly, the cross-sectional nature of this study will make it unable to form a temporal relationship between the outcome and predictor variables. The study is also prone to social desirability bias which could lead to over/ underestimation of the study found. The questionnaire tool used validated questions; however, some respondents had a first language other than Arabic, and the research team, while conducting the questionnaire, observed some difficulty in Arabic comprehension in some environmental services staff members who originate from outside of the country, and do not express themselves in the local language, thus hampering their participation in the study. The use of verbal surveys may be worth considering in future studies or by hospitals wanting to assess the level of knowledge of environmental services staff members. Questions related to attitudes, roles of cleaning, and perceived organizational support were presented toward the end of the questionnaire, which, as previously stated, comprised other questions used for other purposes. The length and dual purpose of the survey may have affected the responses to these questions. In some hospitals, 
environmental services staff members were very skeptical about being asked about their attitudes and perceived organizational support. Despite assurances about confidentiality, some participants expressed concern about their responses being identified by the hospital, especially to questions about perceived organizational support. Conducting a questionnaire on knowledge and practice, separate from attitudes and perceived organizational support, is recommended for future studies.

\section{Conclusion}

Cleaning staffs are on the front lines of fighting this global pandemic. Our results indicate that environmental services staff members have a high level of knowledge and expressed positive attitudes towards health facilities and authorities. They are also aware of the importance of their role. However, there is a perceived lack of organizational support, feedback, and investment in cleaning resources. The attitudes of environmental services staff members should not be ignored, and understanding the determinants of cleaning performance is critical in tailoring interventions to improve hospital cleaning and reduce the risk of infection transmission. The findings of this study will benefit future planning if another outbreak wave occurs.

\section{References}

1. WHO. Coronavirus disease (COVID-2019) press briefings Press briefings. Available from: https://www.who.int/emergencies/diseases/novel-coronavirus-2019/media-resources/press-briefings Accessed on 29 May 2021. 2020.

2. WHO. Modes of transmission of virus causing COVID-19: implications for IPC precaution recommendations. Available from: https://www.who.int/news-room/commentaries/detail/modes-oftransmission-of-virus-causing-covid-19-implications-for-ipc-precaution-recommendations. 2020.

3. Akram MZ. Inanimate surfaces as potential source of 2019-nCoV spread and their disinfection with biocidal agents. Virusdisease. 2020;31(2):94-6.

4. Fiorillo L, Cervino G, Matarese M, D'Amico C, Surace G, Paduano V, et al. COVID-19 Surface Persistence: A Recent Data Summary and Its Importance for Medical and Dental Settings. International journal of environmental research and public health. 2020;17(9).

5. Kothekar AT, Kulkarni AP. Basic Principles of Disinfection and Sterilization in Intensive Care and Anesthesia and Their Applications during COVID-19 Pandemic. Indian J Crit Care Med. 2020;24(11):111424.

6. Otter J, Galletly T. Environmental decontamination 1: what is it and why is it important. Nursing Times. 2018;114(7):32-4. 
7. Matlow AG, Wray R, Richardson SE. Attitudes and beliefs, not just knowledge, influence the effectiveness of environmental cleaning by environmental service workers. American journal of infection control. 2012;40(3):260-2.

8. WHO. Cleaning and disinfection of environmental surfaces in the context of COVID-19: interim guidance, 15 May 2020 (No. WHO/2019-nCoV/Disinfection/2020.1). Accessed on 29 May 2021. 2020.

9. Abou-Abbas L, Nasser Z, Fares Y, Chahrour M, El Haidari R, Atoui R. Knowledge and practice of physicians during COVID-19 pandemic: a cross-sectional study in Lebanon. BMC public health. 2020;20(1):1474.

10. Nasser Z, Fares Y, Daoud R, Abou-Abbas L. Assessment of knowledge and practice of dentists towards Coronavirus Disease (COVID-19): a cross-sectional survey from Lebanon. BMC oral health. 2020;20(1):281.

11. Zeenny RM, Ramia E, Akiki Y, Hallit S, Salameh P. Assessing knowledge, attitude, practice, and preparedness of hospital pharmacists in Lebanon towards COVID-19 pandemic: a cross-sectional study. Journal of pharmaceutical policy and practice. 2020;13:54.

12. Saadeh D, Sacre H, Hallit S, Farah R, Salameh P. Knowledge, attitudes, and practices toward the coronavirus disease 2019 (COVID-19) among nurses in Lebanon. Perspectives in psychiatric care. 2020.

13. Adhikari SP, Meng S, Wu YJ, Mao YP, Ye RX, Wang QZ, et al. Epidemiology, causes, clinical manifestation and diagnosis, prevention and control of coronavirus disease (COVID-19) during the early outbreak period: a scoping review. Infectious diseases of poverty. 2020;9(1):29.

14. WHO. Infection prevention and control during health care when COVID-19 is suspected: interim guidance, 19 March 2020 (No. WHO/2019-nCoV/IPC/2020.3). Accessed on 29 May 2021. 2020.

15. Glanz K, Rimer BK, Viswanath K. Health behavior and health education: theory, research, and practice: John Wiley \& Sons; 2008.

16. CDC. Cleaning and Disinfecting Your Facility. Available from: https://www.cdc.gov/coronavirus/2019-ncov/community/disinfecting-building-facility.html. 2021.

17. Beaton DE, Bombardier C, Guillemin F, Ferraz MB. Guidelines for the process of cross-cultural adaptation of self-report measures. Spine. 2000;25(24):3186-91.

18. Kasa AS, Temesgen WA, Workineh Y, Tesfaye TD, Kerie S, Amsalu E, et al. Knowledge towards standard precautions among healthcare providers of hospitals in Amhara region, Ethiopia, 2017: a cross sectional study. Archives of public health = Archives belges de sante publique. 2020;78(1):127.

19. Tenna A, Stenehjem EA, Margoles L, Kacha E, Blumberg HM, Kempker RR. Infection control knowledge, attitudes, and practices among healthcare workers in Addis Ababa, Ethiopia. Infection control 
and hospital epidemiology. 2013;34(12):1289-96.

20. Ayed A. Knowledge and practice of nursing staff towards infection control measures in the Palestinian hospitals. 2015.

21. Sarani H, Balouchi A, Masinaeinezhad N, Ebrahimitabas E. Knowledge, Attitude and Practice of Nurses about Standard Precautions for Hospital-Acquired Infection in Teaching Hospitals Affiliated to Zabol University of Medical Sciences (2014). Global journal of health science. 2015;8(3):193-8.

22. Jones DL, Baluja MQ, Graham DW, Corbishley A, McDonald JE, Malham SK, et al. Shedding of SARS-CoV-2 in feces and urine and its potential role in person-to-person transmission and the environment-based spread of COVID-19. The Science of the total environment. 2020;749:141364.

23. Bhagavathula AS, Aldhaleei WA, Rahmani J, Mahabadi MA, Bandari DK. Novel coronavirus (COVID-19) knowledge and perceptions: a survey on healthcare workers. MedRxiv. 2020.

24. Bernstein DA, Salsgiver E, Simon MS, Greendyke W, Eiras DP, Ito M, et al. Understanding Barriers to Optimal Cleaning and Disinfection in Hospitals: A Knowledge, Attitudes, and Practices Survey of Environmental Services Workers. Infection control and hospital epidemiology. 2016;37(12):1492-5.

25. Russell D, Dowding DW, McDonald MV, Adams V, Rosati RJ, Larson EL, et al. Factors for compliance with infection control practices in home healthcare: findings from a survey of nurses' knowledge and attitudes toward infection control. American journal of infection control. 2018;46(11):1211-7.

26. Geberemariyam BS, Donka GM, Wordofa B. Assessment of knowledge and practices of healthcare workers towards infection prevention and associated factors in healthcare facilities of West Arsi District, Southeast Ethiopia: a facility-based cross-sectional study. Archives of public health $=$ Archives belges de sante publique. 2018;76:69.

27. Allington D, Duffy B, Wessely S, Dhavan N, Rubin J. Health-protective behaviour, social media usage and conspiracy belief during the COVID-19 public health emergency. Psychological medicine. 2020:1-7.

28. Chon MG, Park H. Predicting Public Support for Government Actions in a Public Health Crisis: Testing Fear, Organization-Public Relationship, and Behavioral Intention in the Framework of the Situational Theory of Problem Solving. Health communication. 2021;36(4):476-86.

29. Teshager FA, Engeda EH, Worku WZ. Knowledge, Practice, and Associated Factors towards Prevention of Surgical Site Infection among Nurses Working in Amhara Regional State Referral Hospitals, Northwest Ethiopia. Surgery research and practice. 2015;2015:736175.

30. Mukwato K, Ngoma C, Maimbolwa M. Compliance With Infection Prevention Guidelines By Health Care Workers at Ronald Ross General Hospital Mufulira District. Medical journal of Zambia. 2009;35:110- 
6.

31. CDC. Infection Prevention and Control Assessment Tool for Acute Care Hospitals. Available from: https://www.cdc.gov/infectioncontrol/pdf/icar/hospital.pdf. Accessed on 29 May 2021. . 2016.

32. Desta M, Ayenew T, Sitotaw N, Tegegne N, Dires M, Getie M. Knowledge, practice and associated factors of infection prevention among healthcare workers in Debre Markos referral hospital, Northwest Ethiopia. BMC health services research. 2018;18(1):465.

33. Hossain MA, Rashid MUB, Khan MAS, Sayeed S, Kader MA, Hawlader MDH. Healthcare Workers' Knowledge, Attitude, and Practice Regarding Personal Protective Equipment for the Prevention of COVID19. Journal of multidisciplinary healthcare. 2021;14:229-38.

34. Delgado Naranjo J, Villate Navarro JI, Sota Busselo M, Martínez Ruíz A, Hernández Hernández JM, Torres Garmendia MP, et al. Control of a Clonal Outbreak of Multidrug-Resistant Acinetobacter baumannii in a Hospital of the Basque Country after the Introduction of Environmental Cleaning Led by the Systematic Sampling from Environmental Objects. Interdisciplinary perspectives on infectious diseases. 2013;2013:582831.

\section{Tables}




\begin{tabular}{|c|c|c|}
\hline & $\mathrm{n}$ & $\%$ \\
\hline \multicolumn{3}{|l|}{ Gender } \\
\hline Male & 207 & $45.70 \%$ \\
\hline Female & 246 & $54.30 \%$ \\
\hline \multicolumn{3}{|l|}{ Age } \\
\hline $21-30$ years & 152 & $33.55 \%$ \\
\hline $31-40$ years & 146 & $32.23 \%$ \\
\hline $41-50$ years & 125 & $27.59 \%$ \\
\hline More than 50 years & 30 & $6.62 \%$ \\
\hline \multicolumn{3}{|l|}{ Nationality } \\
\hline Lebanese & 373 & $82.34 \%$ \\
\hline Other & 80 & $17.75 \%$ \\
\hline \multicolumn{3}{|l|}{ Marital status } \\
\hline Married & 297 & $65.56 \%$ \\
\hline Others* & 156 & $34.44 \%$ \\
\hline \multicolumn{3}{|l|}{ Educational level } \\
\hline Middle School degree or less & 311 & $68.65 \%$ \\
\hline Secondary or BT degree or more & 142 & $31.35 \%$ \\
\hline \multicolumn{3}{|l|}{ Health status } \\
\hline Fair & 21 & $4.64 \%$ \\
\hline Average & 25 & $5.52 \%$ \\
\hline Good & 407 & $89.85 \%$ \\
\hline \multicolumn{3}{|l|}{ Presence of comorbidities } \\
\hline No & 328 & $72.41 \%$ \\
\hline Yes & 125 & $27.59 \%$ \\
\hline \multicolumn{3}{|l|}{ Type of hospital } \\
\hline Private & 347 & $76.60 \%$ \\
\hline Public & 106 & $23.40 \%$ \\
\hline \multicolumn{3}{|l|}{ Income } \\
\hline Less than 1 Million L.L & 366 & $80.79 \%$ \\
\hline 1-2 Millions L.L & 84 & $18.54 \%$ \\
\hline More than 2 Millions L.L & 3 & $0.66 \%$ \\
\hline \multicolumn{3}{|c|}{ Years of experience in hospital cleaning } \\
\hline Less than 3 years & 217 & $47.90 \%$ \\
\hline 3 years or more & 236 & $52.10 \%$ \\
\hline Total & 453 & $100 \%$ \\
\hline
\end{tabular}


11: Knowledge regarding COVID-19 symptoms and signs

in clinical symptoms of COVID-19 are fever, fatigue, tgh and myalgia

sons with COVID-19 will develop severe cases and

lie

derly and those having chronic illnesses are more likely jvere cases

12 : Knowledge of COVID-19 mode of transmission

-19 can be transmitted from person to person via cough zezes

-19 can be transmitted by urine and feces of an infected

19 can be transmitted by kissing, hugging, shaking ith an infected person

cted person with COVID-19 can be asymptomatic and

the infection to others

1 3: Knowledge of Novel Coronavirus prevention and treatment

-19 can be prevented by regular washing hands with Id water and also by using sanitizers

-19 can be prevented by using a mask

3 , there is no specific treatment for COVID-19

VID-19 exposure should be immediately reported to the ll call center

mber of people visiting the patient room (in contact e patient) should be minimized

ie spent by the cleaner in the room of the COVID-19 should be reduced

14: Knowledge regarding cleaning and disinfection

faces that have been in contact with the ill person(s), ; toilet, handwashing basins, and baths, should be $\mathrm{l}$, then disinfected

ig should always be performed first, followed by stion for surfaces and items touched by COVID-19 case. se of bleach is not suitable, or potentially damaging to face (on devices like telephones and remote-control ent), $70 \%$ alcohol could be used.

reparing bleach solution, concentration should be red

surface is required after the application of disinfectant leaning, using disposable cleaning materials whenever e hould be bagged before being removed from the room is not require special laundering quency of cleaning of the room of COVID-19 patient be reduced

ig staff should wear PPEs when visiting the room of -19 patient

15 : Knowledge regarding the risk of getting COVID-19 $\mathrm{k}$ of COVID-19 infection depends on the type of surface the virus is present $\mathrm{k}$ of COVID-19 infection depends on the concentration ; k of COVID-19 infection depends time since the infected left the place

\begin{tabular}{|r|r|}
\hline $421(92.9 \%)$ & $32(7.1 \%)$ \\
\hline $309(68.2 \%)$ & $144(31.8 \%)$ \\
\hline $422(93.2 \%)$ & $31(6.9 \%)$ \\
\hline $438(96.7 \%)$ & $15(3.3 \%)$ \\
\hline $210(46.4 \%)$ & $173(53.7 \%)$ \\
\hline $421(92.9 \%)$ & $32(7.1 \%)$ \\
\hline $419(92.5 \%)$ & $34(7.5 \%)$ \\
\hline
\end{tabular}

\begin{tabular}{r|r} 
orrect & Incorrect \\
\hline $\mathrm{n}(\%)$ & $\mathrm{n}(\%)$
\end{tabular}

\begin{tabular}{|r|r|}
\hline $438(96.7 \%)$ & $15(3.3 \%)$ \\
\hline $435(96 \%)$ & $18(4 \%)$ \\
\hline $422(66.9 \%)$ & $150(33.1 \%)$ \\
\hline $416(91.8 \%)$ & $31(6.9 \%)$ \\
\hline $387(85.4 \%)$ & $66(14.6 \%)$ \\
\hline $434(95.8 \%)$ & $19(4.2 \%)$ \\
\hline $408(90.1 \%)$ & $45(9.9 \%)$ \\
\hline $326(72 \%)$ & $127(28 \%)$ \\
\hline $422(93.2 \%)$ & $31(6.9 \%)$ \\
\hline $254(56.1 \%)$ & $199(43.9 \%)$ \\
\hline $399(88.1 \%)$ & $54(11.9 \%)$ \\
\hline $435(96 \%)$ & $18(3.9 \%)$ \\
\hline $304(67.1 \%)$ & $149(32.8 \%)$ \\
\hline $418(92.3 \%)$ & $35(7.7 \%)$ \\
\hline $353(77.9 \%)$ & $100(22.1 \%)$ \\
\hline $314(69.3 \%)$ & $139(30.7 \%)$ \\
\hline $330(72.8 \%)$ & $123(27.2 \%)$ \\
\hline
\end{tabular}


3: Attitudes of housekeepers and cleaners towards health facility, health authorities leaning

\begin{tabular}{|c|c|c|c|}
\hline & Disagree & Neutral & Agree \\
\hline & $\mathbf{n}(\%)$ & $\mathbf{n}(\%)$ & $\mathbf{n}(\%)$ \\
\hline it safety is a priority in this hospital & $18(3.9 \%)$ & $24(5.4 \%)$ & $411(87.7 \%)$ \\
\hline $\begin{array}{l}\text { ospital is always trying to find new ways to } \\
\text { 've hygiene }\end{array}$ & $50(11.1 \%)$ & $190(41.9 \%)$ & $213(47 \%)$ \\
\hline $\begin{array}{l}\text { ospital provides me by all the equipment } \\
\mathrm{d} \text { for cleaning and sterilization }\end{array}$ & $15(3.3 \%)$ & $27(6 \%)$ & $411(90.7 \%)$ \\
\hline $\begin{array}{l}\text { ospital does not appreciate any further } \\
\text { exert from my part }\end{array}$ & $242(53.4 \%)$ & $58(12.8 \%)$ & $153(33.8 \%)$ \\
\hline $\begin{array}{l}\text { ospital ignores any complaints or requests } \\
\text { my part }\end{array}$ & $287(63.4 \%)$ & $63(13.9 \%)$ & $103(22.8 \%)$ \\
\hline $\begin{array}{l}\text { ospital really cares about my safety and } \\
\text { alth }\end{array}$ & $21(4.65 \%)$ & $21(4.65 \%)$ & $411(90.7 \%)$ \\
\hline $\begin{array}{l}\text { if you do my best, the hospital will not } \\
\text { ciate it }\end{array}$ & $252(55.6 \%)$ & $66(14.6 \%)$ & $135(29.8 \%)$ \\
\hline $\begin{array}{l}\text { ospital takes care of my general } \\
\text { action at work }\end{array}$ & $72(13.6 \%)$ & $82(18.1 \%)$ & $309(68.2 \%)$ \\
\hline ospital does not take much interest in me & $253(55.9 \%)$ & $77(17 \%)$ & $123(27.1 \%)$ \\
\hline $\begin{array}{l}\text { it easy to ask my supervisor if help or } \\
\text { כ are needed }\end{array}$ & $13(2.9 \%)$ & $17(3.8 \%)$ & $423(93.3 \%)$ \\
\hline $\begin{array}{l}\text { rinfection prevention measures are well } \\
\text { mented at hospital }\end{array}$ & $21(4.6 \%)$ & $37(8.2 \%)$ & $395(87.2 \%)$ \\
\hline $\begin{array}{l}\text { s the hospital has done its part in raising } \\
\text { zness about the risk of catching COVID-19 } \\
\text { ow to prevent it }\end{array}$ & $18(4 \%)$ & $30(6.6 \%)$ & $405(90.4 \%)$ \\
\hline \multicolumn{4}{|l|}{ des toward cleaning and disinfection } \\
\hline $\begin{array}{l}\text { ve that cleaning and disinfecting surfaces } \\
\text { ctive for eliminating COVID-19 }\end{array}$ & $3(0.7 \%)$ & $61(13.5 \%)$ & $389(85.8 \%)$ \\
\hline $\begin{array}{l}\text { K that PPEs can protect me from catching } \\
\text { D-19 }\end{array}$ & $18(4 \%)$ & $39(8.6 \%)$ & $396(87.4 \%)$ \\
\hline $\begin{array}{l}\text { ve that regular hand washing could } \\
\text { nt the COVID-19 infection }\end{array}$ & $14(3.1 \%)$ & $39(8.6 \%)$ & $400(88.3 \%)$ \\
\hline \multicolumn{4}{|l|}{ des towards health authorities } \\
\hline $\begin{array}{l}\mathrm{r} \text { that MOPH has played her preventive } \\
\text { t the hospital (providing PPEs...) }\end{array}$ & $50(11.1 \%)$ & $82(18.1 \%)$ & $321(76.9 \%)$ \\
\hline $\begin{array}{l}\text { confidence that Lebanon can win the } \\
\text { against the COVID-19 }\end{array}$ & $74(16.4 \%)$ & $79(17.4 \%)$ & $300(66.2 \%)$ \\
\hline
\end{tabular}




\begin{tabular}{|c|c|c|c|}
\hline es & Never & Occasionally & $\begin{array}{l}\text { All the } \\
\text { times }\end{array}$ \\
\hline & $\mathrm{n}(\%)$ & $\mathrm{n}(\%)$ & $\mathrm{n}(\%)$ \\
\hline $\begin{array}{l}\text { hands with soap and water, and also } \\
\text { sinfectants regularly }\end{array}$ & $6(1.3 \%)$ & $35(1.3 \%)$ & $412(90.9 \%)$ \\
\hline $\begin{array}{l}\text { ning social distance with everyone in the } \\
(1.5 \mathrm{~m})\end{array}$ & $3(0.7 \%)$ & $107(23.6 \%)$ & $343(75.7 \%)$ \\
\hline I face mask all the time at the hospital & $12(2.6 \%)$ & $27(6 \%)$ & 414(91.4\%) \\
\hline 9 the presence in crowded places & $9(2 \%)$ & $56(12.4 \%)$ & $388(85.7 \%)$ \\
\hline 9 touching surfaces than touching eyes or & $9(2 \%)$ & $25(5.5 \%)$ & $419(92.5 \%)$ \\
\hline to the prevention measures requested by & $6(1.3 \%)$ & $29(6.4 \%)$ & $418(92.3 \%)$ \\
\hline ing cough and sneeze etiquette & $3(0.7 \%)$ & $24(5.3 \%)$ & $426(94 \%)$ \\
\hline $\begin{array}{l}\text { g the availability of the needed cleaning } \\
\text { with my supervisor before starting }\end{array}$ & $3(0.7 \%)$ & $53(11.7 \%)$ & $397(87.6 \%)$ \\
\hline $\begin{array}{l}\text { I and disinfecting common areas at } \\
\text { s (such as rest rooms, halls, reception, } \\
\text { s and lifts) }\end{array}$ & $3(0.7 \%)$ & $46(10.2 \%)$ & $404(89.2 \%)$ \\
\hline $\begin{array}{l}\text { and disinfecting surfaces and objects } \\
\text { frequently touched, such as handles, } \\
\text { buttons, handrails, doorknobs and } \\
\text { ars }\end{array}$ & $3(0.7 \%)$ & $34(7.5 \%)$ & $416(91.8 \%)$ \\
\hline $\begin{array}{l}\text { the room where disinfectant solution is } \\
\text { d used aerated and Labelling the prepared } \\
\text { of disinfectant }\end{array}$ & $12(2.6 \%)$ & $61(14.1 \%)$ & $377(83.2 \%)$ \\
\hline $\begin{array}{l}\text { ig the manufacturer's instructions to } \\
\text { hat disinfectants are prepared and } \\
\text { safely. }\end{array}$ & $9(2 \%)$ & $31(6.8 \%)$ & $413(91.2 \%)$ \\
\hline $\begin{array}{l}\text { J appropriate PPE when visiting COVID-19 } \\
\text { room }\end{array}$ & $3(0.7 \%)$ & $21(4.6 \%)$ & $429(94.7 \%)$ \\
\hline and doffing PPEs appropriately & $5(1.1 \%)$ & $33(7.3 \%)$ & $415(91.6 \%)$ \\
\hline $\begin{array}{l}\text { g regular training on IPC including PPEs } \\
\text { and doffing }\end{array}$ & $11(2.4 \%)$ & $44(9.7 \%)$ & $398(87.9 \%)$ \\
\hline ny hands before and after wearing PPEs & $3(0.7 \%)$ & $26(5.7 \%)$ & $424(93.6 \%)$ \\
\hline $\begin{array}{l}\text { ig laundry carefully to mitigate the risk of } \\
\text { l transmission. }\end{array}$ & $3(0.7 \%)$ & $23(5 \%)$ & $427(94.3 \%)$ \\
\hline $\begin{array}{l}\text { textiles, linens, and clothes in special, } \\
\text { laundry bags }\end{array}$ & $21(4.6 \%)$ & $28(6.2 \%)$ & $404(89.2 \%)$ \\
\hline $\begin{array}{l}\text { I laundry in warm cycles }\left(60-90^{\circ} \mathrm{C}\right) \text { with } \\
\text { ll detergents. }\end{array}$ & $21(4.6 \%)$ & $53(11.7 \%)$ & $379(83.7 \%)$ \\
\hline $\begin{array}{l}\text { disposable items (hand towels, gloves, } \\
\text { masks, tissues) in a container with a lid } \\
\text { owing hospital action plan and national } \\
\text { ons for waste management. }\end{array}$ & $6(1.3 \%)$ & $24(5.3 \%)$ & $423(93.4 \%)$ \\
\hline g COVID-29 news & $30(6.6 \%)$ & $135(29.8 \%)$ & $288(63.6 \%)$ \\
\hline
\end{tabular}


5: Multivariable logistic regression of the factors associated with Cleaners good ices

\begin{tabular}{|c|c|c|c|c|c|c|}
\hline & \multirow{2}{*}{$\begin{array}{c}\begin{array}{c}\text { Poor } \\
\text { practices }\end{array} \\
\mathrm{n}(\%) \\
\end{array}$} & \multirow{2}{*}{$\begin{array}{c}\begin{array}{c}\text { Good } \\
\text { practices }\end{array} \\
\mathrm{n}(\%)\end{array}$} & \multirow[t]{2}{*}{$\begin{array}{c}\mathrm{P}- \\
\text { value }\end{array}$} & \multirow[t]{2}{*}{ aOR } & \multicolumn{2}{|c|}{$\begin{array}{l}\text { 95\% C.I.for } \\
\text { aOR }\end{array}$} \\
\hline & & & & & Lower & Upper \\
\hline \multirow[t]{2}{*}{ er } & & & 0.18 & & & \\
\hline & $19(9.2 \%)$ & $188(90.8 \%)$ & & & & \\
\hline \multirow[t]{2}{*}{ le } & $28(11.4 \%)$ & $218(88.6 \%)$ & & & & \\
\hline & & & $<0.001$ & & & \\
\hline years & $1(0.7 \%)$ & $151(99.3 \%)$ & & 1.000 & & \\
\hline years & $8(5.5 \%)$ & $138(94.5 \%)$ & 0.016 & 0.051 & 0.005 & 0.576 \\
\hline than 41 years & $38(24.5 \%)$ & $117(75.5 \%)$ & $<0.001$ & 0.005 & 0.002 & 0.051 \\
\hline al status & & & 0.608 & & & \\
\hline 3 & $5(4.5 \%)$ & $106(95.5 \%)$ & & & & \\
\hline $\begin{array}{l}\text { s (single, separated } \\
\text { dowed) }\end{array}$ & $15(9.7 \%)$ & $141(90.3 \%)$ & & & & \\
\hline ational level & & & 0.023 & & & \\
\hline e School degree or & $39(12.5 \%)$ & $272(87.5 \%)$ & & 1.000 & & \\
\hline $\begin{array}{l}\text { idary or BT degree } \\
\text { ire }\end{array}$ & $8(5.7 \%)$ & $134(94.3 \%)$ & 0.019 & 2.869 & 0.871 & 9.445 \\
\hline \multirow[t]{3}{*}{ nce of comorbidities } & & & 0.251 & & & \\
\hline & $37(11.3 \%)$ & $291(88.7 \%)$ & & & & \\
\hline & $10(8 \%)$ & $115(92 \%)$ & & & & \\
\hline \multirow[t]{2}{*}{ of hospital } & & & $<0.001$ & & & \\
\hline & $27(25.5 \%)$ & $79(74.5 \%)$ & & 1.000 & & \\
\hline $\mathrm{te}$ & $20(5.8 \%)$ & $327(94.2 \%)$ & $<0.002$ & 10.083 & 3.340 & 30.436 \\
\hline \multicolumn{3}{|c|}{ of experience in hospital cleaning } & $<0.001$ & & & \\
\hline han 3 years & $40(18.43 \%)$ & $177(81.57 \%)$ & & 1 & & \\
\hline rs and more & $7(3 \%)$ & $229(97 \%)$ & 0.001 & 12.942 & 4.214 & 39.747 \\
\hline \multicolumn{3}{|c|}{ ledge regarding COVID-19 symptoms } & 0.006 & & & \\
\hline & $10(43.5 \%)$ & $13(56.5 \%)$ & & & & \\
\hline & $37(8.6 \%)$ & $393(91.4 \%)$ & $0 . .006$ & 9.076 & 1.895 & 43.463 \\
\hline \multicolumn{2}{|c|}{$\begin{array}{l}\text { ledge of COVID-19 mode of } \\
\text { mission }\end{array}$} & & 0.833 & & & \\
\hline & $6(14 \%)$ & $37(86 \%)$ & & & & \\
\hline & $41(10 \%)$ & $369(90 \%)$ & & & & \\
\hline \multirow[t]{3}{*}{ ledge of COVID-19 pr } & evention and & reatment & 0.019 & & & \\
\hline & $6(37.5 \%)$ & $10(62.5 \%)$ & & 1.000 & & \\
\hline & $41(9.4 \%)$ & $396(90.6 \%)$ & 0.015 & 10.717 & 1.594 & 22.051 \\
\hline \multirow[t]{3}{*}{ ledge of cleaning and } & disinfection & & 0.031 & & & \\
\hline & $6(27.3 \%)$ & $16(72.7 \%)$ & & & & \\
\hline & $41(9.5 \%)$ & $390(90.5 \%)$ & 0.035 & 3.939 & 1.099 & 14.126 \\
\hline \multicolumn{3}{|c|}{ ledge about the risk factors of getting COVID-19 } & 0.004 & & & \\
\hline & $10(26.3 \%)$ & $28(73.7 \%)$ & & & & \\
\hline & $37(8.9 \%)$ & $378(91.1 \%)$ & 0.012 & 7.937 & 1.569 & 40.150 \\
\hline \multicolumn{3}{|c|}{ des of Housekeepers towards health facility } & $<0.001$ & & & \\
\hline tive & $16(35.6 \%)$ & $29(64.4 \%)$ & & 1 & & \\
\hline $\mathrm{Ve}$ & $31(7.6 \%)$ & $377(92.4 \%)$ & $<0.001$ & 14.481 & 3.591 & 58.388 \\
\hline \multicolumn{3}{|c|}{$\begin{array}{l}\text { des of Housekeepers towards cleaning and } \\
\text { ection }\end{array}$} & $<0.001$ & & & \\
\hline tive & $23(26.1 \%)$ & $65(73.9 \%)$ & & & & \\
\hline $\mathrm{ve}$ & $24(6.6 \%)$ & $341(93.4 \%)$ & 0.035 & 3.939 & 1.099 & 14.126 \\
\hline des of Housekeepers & towards healt & 1 authorities & 0.021 & & & \\
\hline tive & $27(32.1 \%)$ & $57(67.9 \%)$ & & & & \\
\hline ve & $20(5.4 \%)$ & $349(94.6 \%)$ & 0.032 & 3.303 & 1.106 & 9.863 \\
\hline
\end{tabular}


$* p$-value $<0.05$ is considered significant

\section{Declarations}

\section{Ethics approval and consent to participate:}

Research was performed in line with the principles of the Declaration of the Helsinki as revised in 2008. Written informed consent was obtained from all the participants at recruitment. Participants were informed that all information would be gathered anonymously and handled confidentially. Participation was voluntary, and the questionnaire was collected only in subjects who expressed consent for study participation. As individual participants cannot be identified based on the presented material, this study caused no plausible harm or stigma to participants. The study design assured adequate protection of study participants, and neither includes clinical data about patients nor configures itself as a clinical trial

\section{Funding}

No funding was received.

\section{Availability of data and materials}

The datasets used and analyzed during the current study will not be made publically available but will be available from the corresponding author on reasonable request.

\section{Consent for publication}

Not applicable.

\section{Competing interests}

The author(s) declare that they have no competing interests.

\section{Authors' contributions}

DY developed the project idea. DY, HH and LAA formulated the questionnaire, organized and analyzed the survey. DY, LAA, HH drafted and critically reviewed the paper. All authors read and agreed on the final version.

\section{Acknowledgements}


The authors acknowledge all infection control personnel for their assistance with data collection. The authors also thank all cleaners who participated in the study.

\section{Contributor Information}

Dalal Youssef, Email: dalalyoussef.esu@gmail.com

\section{Supplementary information}

Supplement file

\section{Authors information:}

Dalal Youssef, MSc, MPH, BRM, RSM, PhD candidate, Ministry of public Health, Lebanon, Preventive medicine department

Linda Abou Abbas, MPH, PHD, Ministry of Public Health,Lebanon, Epidemiological surveillance unit Hamad Hassan, PhD, Ministry of Public Health, Lebanon

\section{Figures}

Knowledge domains:

\section{Housekeepers' and cleaners' Knowledge domains}

Overall knowledge score

Knowledge regarding the risk of getting COVID-19

Knowledge regarding cleaning and disinfection

Knowledge of Novel Coronavirus prevention and treatment

Knowledge of COVID-19 mode of transmission

Knowledge regarding COVID-19 symptoms and signs

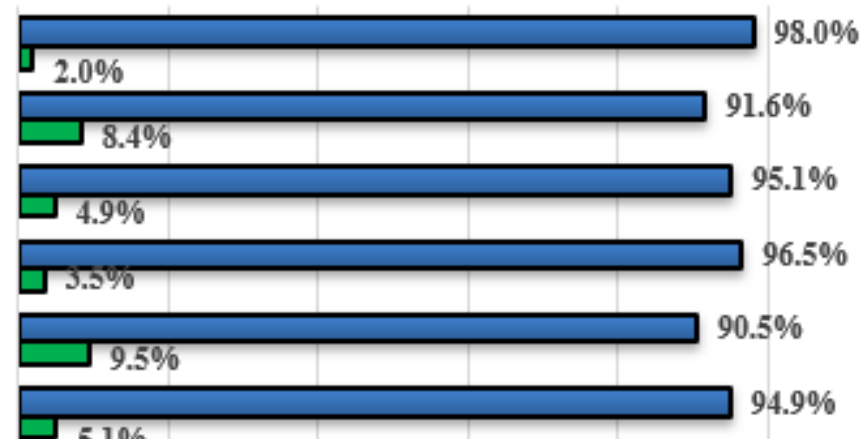

$\begin{array}{lllllll}0.0 \% & 20.0 \% & 40.0 \% & 60.0 \% & 80.0 \% & 100.0 \% & 120.0 \% \\ \text { 口Good \% } & \text { 口Poor \% } & & & & & \end{array}$

Figure 1

Housekeepers and cleaners knowledge domains 


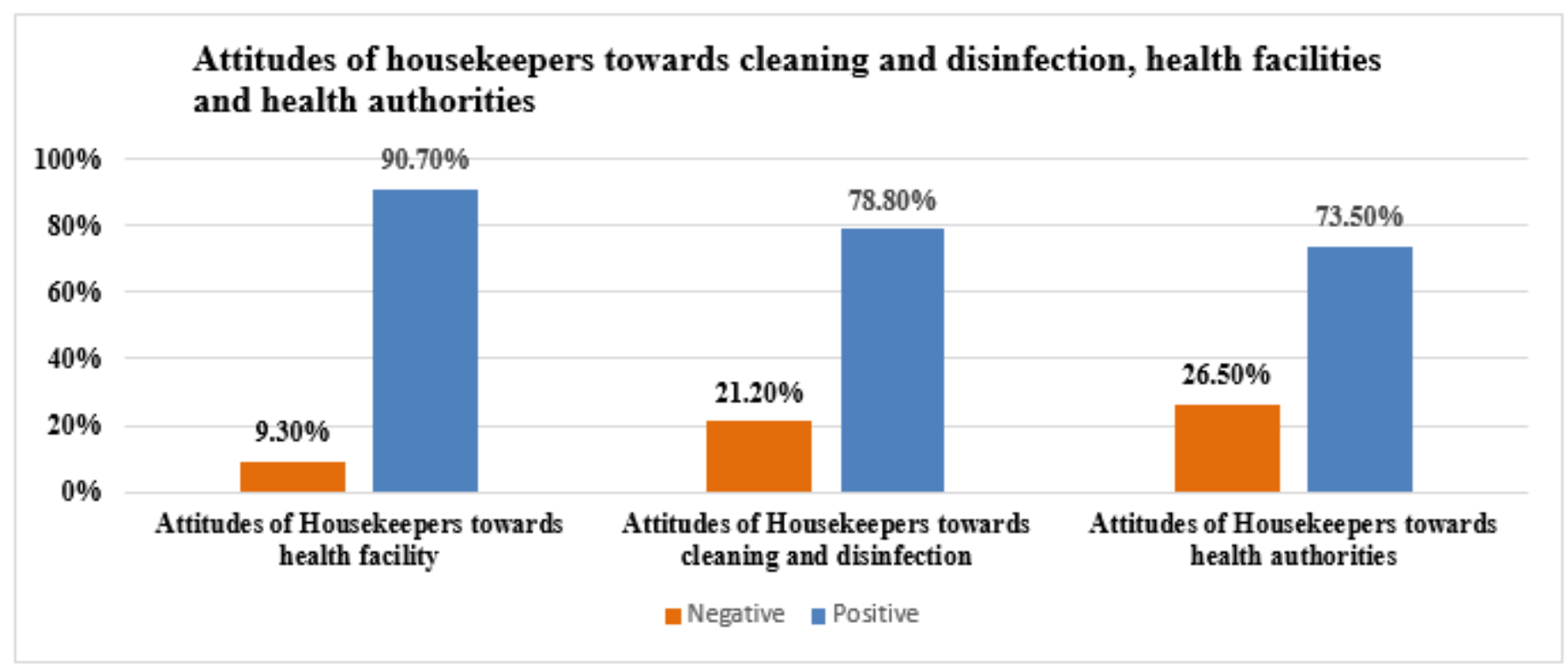

Figure 2

Attitudes of Cleaners towards health facility, health authorities and cleaning procedures

\section{Sources used by Cleaners to get information about COVID-19}

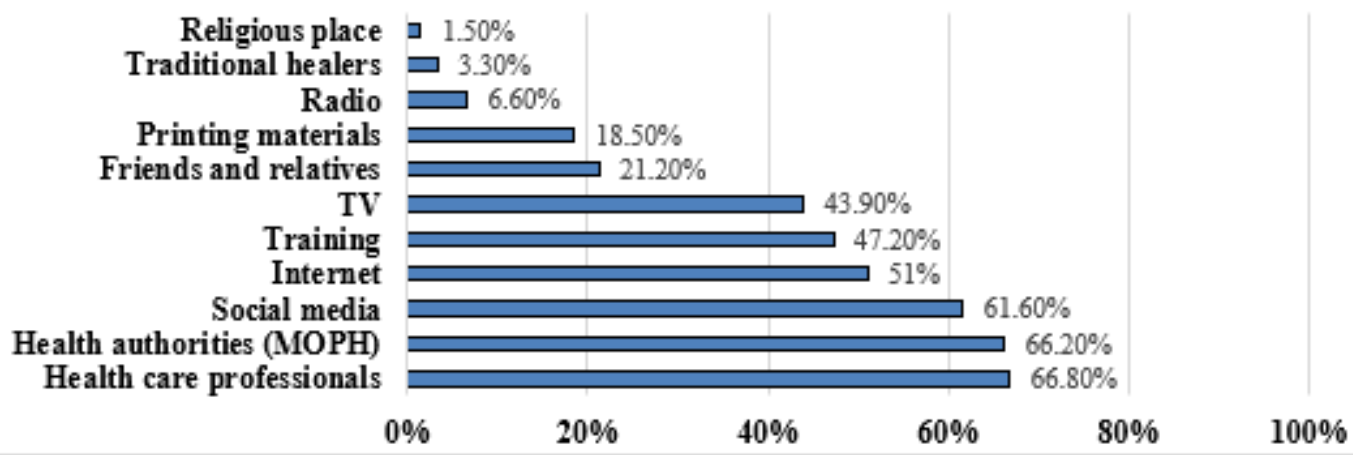

Figure 3

Sources of information used by Cleaners 


\section{Reliability of used sources of information as perceived by Cleaners}

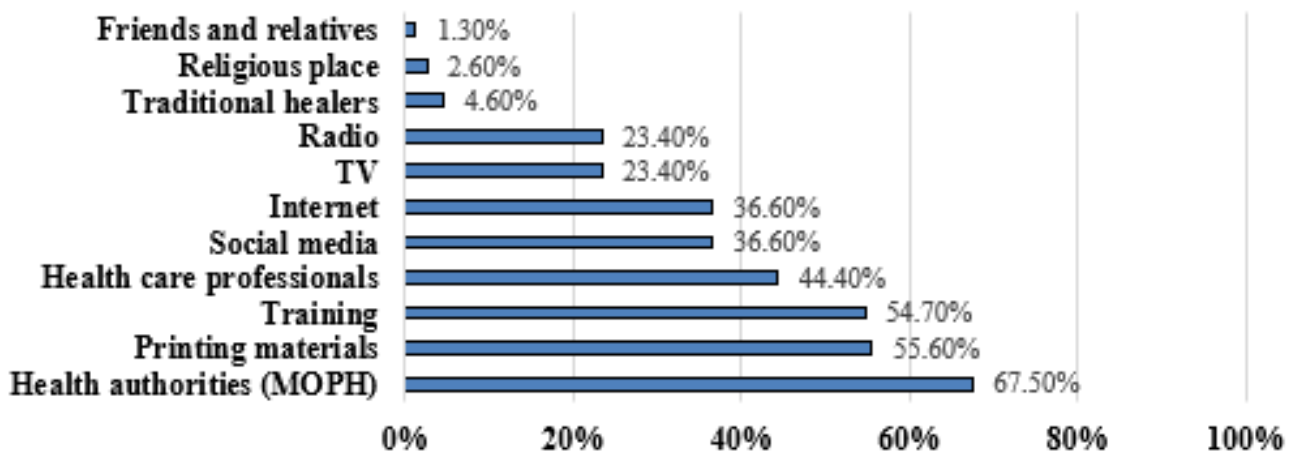

\section{Figure 4}

Reliability of sources of information as perceived by Cleaners 